\title{
Nanoporous Pt-based catalysts prepared by chemical dealloying of magnetron-sputtered Pt-Cu thin films for the catalytic combustion of hydrogen
}

F. Giarratano, G.M. Arzac,* V. Godinho,* D. Hufschmidt, M.C. Jiménez de Haro, O. Montes, and A. Fernández*

Instituto de Ciencia de Materiales de Sevilla (CSIC-Univ. Sevilla), Avda. Américo Vespucio 49, 41092-Sevilla, Spain.

* Corresponding authors: (G.M. Arzac), godinho@icmse.csic.es (V. Godinho).

\begin{abstract}
In this work, we prepared SiC-supported Pt-Cu thin films by magnetron sputtering for use as catalysts for the combustion of hydrogen under oxidizing conditions. We tested the catalysts as prepared and after chemical dealloying. A methodology is presented to fabricate catalytic thin films of a desired composition with tailored magnetron targets with lower Pt consumption. The deposition gas was changed to prepare columnar (Ardeposited) and closed-porous (He-deposited) films to study the effect of the microstructure on the activity. The effect of composition was also studied for the columnar samples. The as-prepared Pt-Cu thin films showed significant activity only at temperatures higher than $100^{\circ} \mathrm{C}$. Dealloying permitted an increase in the activity to achieve near room-temperature activity. The dealloyed closed-porous He-deposited sample was the most active, being able to convert as much as $13.15 \mathrm{~L}_{\mathrm{H} 2} \cdot \mathrm{min}^{-1} \cdot \mathrm{g}_{\mathrm{Pt}}{ }^{-1}$ at $70^{\circ} \mathrm{C}\left(\mathrm{E}_{\mathrm{a}}=1 \mathrm{~kJ} \cdot \mathrm{mol}^{-1}\right)$. This sample was preferentially dealloyed on the surface, yielding
\end{abstract}


an almost pure Pt shell (96\% at. Pt) and a Cu-depleted interior (71\% at. Pt). This compositional inhomogeneity enabled the sample to achieve enhanced activity compared to the Ar-deposited columnar sample (with similar initial composition, but uniformly dealloyed), probably due to the compressive surface lattice strain. The dealloyed closedporous He-deposited sample was shown to be durable over five cycles.

\section{Keywords}

Hydrogen combustion, Pt-Cu thin films, magnetron sputtering, nanoporous $\mathrm{Pt}$, dealloying

\section{Introduction}

The catalytic combustion of hydrogen $(\mathrm{CHC}$, reaction 1$)$ is a highly exothermic reaction $\left(-286 \mathrm{~kJ} \cdot \mathrm{mol}^{-1}\right)$ that is very interesting from both a fundamental and an applied point of view. Due to its relative simplicity it can be considered as model catalytic oxidation reaction in the gas phase, and has applications in heaters for domestic or industrial use (for example, cooking, heating spaces, floors and walls, drying and other heating industrial processes) or in safety devices [1-5].

$$
\mathrm{H}_{2}(\mathrm{~g})+1 / 2 \mathrm{O}_{2}(\mathrm{~g}) \rightarrow \mathrm{H}_{2} \mathrm{O}(\mathrm{g})
$$

Regarding safety applications, the $\mathrm{CHC}$ can be employed as a controllable means to eliminate the undesired amounts of hydrogen in installations such as in the nuclear industry or fuel cell-based power generation devices [3-8]. The elimination of residual hydrogen from the exhaust gases from fuel cells requires the use of catalysts that are active at room temperature (RT). According to previous studies, only Pt and Pd can catalyse the reaction at low temperatures [1]. However, these are scarce and precious metals, increasing the costs of any possible application. For this reason, the development 
of highly active and stable Pt or Pd-based catalysts with low precious metal content by cost-effective methods is of utmost interest currently.

Many efforts have been made to achieve this goal. The reduction in metal loading in Ptimpregnated catalysts, alloying with other less expensive metals such as $\mathrm{Ni}, \mathrm{Cu}$ and $\mathrm{Co}$, the use of reducible supports such as $\mathrm{CeO}_{2}$ and ionic $\mathrm{Pt}$ or $\mathrm{Pd}$ substitution on oxidic supports, are the most employed methods in the literature [4-5, 9-11].

Another strategy to obtain highly active noble metal catalysts for $\mathrm{CHC}$ is dealloying. Dealloying is an ancient practice based on the selective dissolution of the less noble component of a bimetallic precursor to obtain a nanoporous (np) material enriched in the nobler component [12-14]. This process can be conducted either electrochemically or chemically reducing the consumption of noble elements by more than $70 \%$ [15-20]. Compared to electrochemical dealloying, chemical dealloying is more practical and scalable in the catalyst industry [20] and can also be applied for supported films on nonconductive supports. Dealloying has been successfully used to enhance the catalytic activity of Pt-Cu nanoparticles or nanofilms for the oxygen reduction reaction (ORR) [1523.a]. This process leads to the formation of a $\mathrm{Cu}$-depleted interior covered by a $\mathrm{Pt}$ surface layer that is compressively strained, resulting in a downshift and broadening of the Pt d-band and leading to a weaker oxygen bond strength and higher ORR activity[19, 22-23.a].

To our knowledge, the study of the CHC over dealloyed catalysts has not been reported before. In this work, we have prepared Pt-Cu alloy thin films by magnetron sputtering to investigate the effect of chemical dealloying on the activity for the $\mathrm{CHC}$ under conditions that simulate the composition of the exhaust gas of a fuel cell $\left(1 \% \mathrm{v} / \mathrm{v} \mathrm{H}_{2}\right.$ in air). Dealloyed Pd-Cu materials were reported to be less strained than their Pt-containing 
counterparts, and for this reason they were excluded from this work, despite the lower cost of Pd with respect to Pt [23.b].

Magnetron sputtering, a versatile deposition technique widely used in industry, permits the design of catalytic thin films with controlled microstructure and composition, over a wide variety of supports to obtain model catalysts for structure-performance studies [2427]. Pt-Cu catalysts fabricated by magnetron sputtering have been previously investigated either by co-sputtering from $\mathrm{Cu}$ and $\mathrm{Pt}$ targets or by sputtering alloyed targets with the desired composition [22,24]. Their structure before and after dealloying has been correlated with the ORR activity [22].

In this work, we have developed a preparation process that minimizes the Pt consumption. We propose a cost-effective strategy to prepare alloy coatings using a $\mathrm{Cu}$ target with $\mathrm{Pt}$ strips. The approach is flexible regarding target composition (by adding or removing strips) in contrast to an alloy target of fixed composition. Additionally, over the last years, we have developed in our laboratory a simple methodology for the bottom-up fabrication of closed-porous coatings using helium plasmas [28-29]. The influence of this singular microstructure on the chemical dealloying process and on the CHC activity is investigated here and compared to columnar coatings deposited with Ar of similar composition. We prepared two low Pt-content Pt-Cu samples with similar compositions and different microstructures (i.e., columnar vs. closed porous) by using different sputtering gases (Ar and He respectively). We also prepared a third sample with higher Pt content using Ar as the sputtering gas to study the effect of composition for columnar films. The influence of microstructure and composition on the activity of both the asprepared and dealloyed thin films will be discussed in this paper. 


\section{Experimental Section}

\section{Samples preparation}

Coatings were deposited by sputtering under pure Ar or He atmosphere using a 2" magnetron from the Thin Film Consulting Company. A scheme of the deposition geometry is represented in Fig. 1a. Pt-Cu targets were prepared from a pure copper target (Kurt J. Lesker, 99.99\% pure, 5 mm thick) on which Pt strips (Goodfellow, 99.99\% pure, $0.15 \mathrm{~mm}$ thick) were radially distributed as shown schematically in Fig. 1 b. Two Pt-Cu targets were prepared by varying the number of the Pt strips (see Table 1). A pure copper target was also used to prepare pure $\mathrm{Cu}$ reference coatings. The base pressure before deposition was $10^{-6}$ mbar while the working pressure was $4.8 \times 10^{-2}$ mbar (for either Ar or He, $99.9995 \%$ purity). The deposition power was $100 \mathrm{~W}$ in RF mode. The substrates to be coated were placed on a rotary sample-holder to ensure homogeneous deposition. The cathode was placed parallel to the substrates at a distance of $5 \mathrm{~cm}$ from the sampleholder (Fig. 1a). Table 1 summarizes the deposition conditions employed as well as deposition times, deposition rates and thicknesses of the fabricated samples.

The composition of the coatings was determined after adequate digestion by inductively coupled plasma atomic emission spectroscopy (ICP-AES) as described in the subsection "Characterization" in this experimental part. Table 1 also summarizes the abbreviated names used for all of the coatings, which were based on the obtained coating compositions and the process gas used. The precise substrate used will be indicated when necessary. All of the coatings were deposited in the conditions described above directly onto different substrates: i) PTFE (polytetrafluoroethylene) membranes (Pall Corporation, $0.02 \mu \mathrm{m}$ pore size, polypropylene backed), used as received, for characterization. ii) A commercial alumina bonded $\mathrm{SiC}$ monolith foam (VUKOPOR®S100 from LANIK with 
100 pores per inch (ppi)) for the catalytic studies of the $\mathrm{CHC}$ reaction and the characterization [8]. These substrates were washed in an ultrasonic bath successively with distilled water and ethanol/acetone $(1: 1)$ and then dried in vacuum at $110^{\circ} \mathrm{C}$ overnight. iii) $\mathrm{Si}(100)$ pieces cleaned with acetone and dried in a nitrogen flow, for characterization. Dealloyed samples (d-samples) were obtained by treating the films under concentrated nitric acid (14.4 M) for $5 \mathrm{~min}$ at room temperature. After dealloying, the samples were washed thoroughly with deionized water until neutral $\mathrm{pH}$ and dried in a vacuum oven at $110^{\circ} \mathrm{C}$

\section{Characterization}

Scanning Electron Microscopy (SEM) analyses were performed on silicon and SiC foam- supported films in a high-resolution SEM-FEG (Field Emission Gun) microscope (Hitachi S4800) operated at 5keV for imaging and at $20 \mathrm{keV}$ for compositional analysis. The microscope is equipped with a Bruker X-Flash 4010 EDX (Energy Dispersive X-ray) detector.

X-ray diffraction (XRD) measurements on the Si-supported films were performed using $\mathrm{Cu} \mathrm{K} \alpha$ radiation in a Siemens D5000 diffractometer in a Bragg-Brentano configuration in the $2 \theta$ angle range of 10-90 degrees. Crystallite size was calculated using the X-Pert High Score Plus software with a 0.9 value for Scherrer's constant.

X-ray photoelectron spectroscopy (XPS) spectra of the PTFE-supported films were recorded with a SPECS electron spectrometer, equipped with a PHOIBOS 150 hemispherical analyser, using $\mathrm{Al} \mathrm{Ka}$ radiation with a $35 \mathrm{eV}$ pass energy at the normal emission take-off angle. The spectra were calibrated with the signal of C $1 \mathrm{~s}$ at $284.6 \mathrm{eV}$ from adventitious carbon. 
For TEM (transmission electron microscopy) studies, SiC-supported dealloyed Pt-Cu films were ground in a mortar to obtain a powder. Measurements were performed employing a Philips CM20 microscope (operated at 200kV) and an FEI Tecnai G2 F30 FEG (field emission gun) microscope (operated at 300kV).

Samples deposited on PTFE were submitted to digestion before being analysed by ICPAES (inductively coupled plasma atomic emission spectroscopy) at the CITIUS laboratories (University of Seville) to quantify the $\mathrm{Pt}$ and $\mathrm{Cu}$ atomic percentages.

\section{Catalytic tests}

The catalytic combustion of hydrogen was tested under oxidizing conditions for the monolithic SiC-supported thin film catalysts in a quartz reactor (20 $\mathrm{mm}$ diameter, 500 mm length). The film thickness (300 nm) was optimized to achieve a sigmoid conversion $v s$. temperature curve. These conditions are essential to evaluate and compare catalytic properties (activation energy, $\mathrm{T}_{50}$, etc.) in a kinetic regime. Under these conditions, the heat released by the reaction is negligible. Unless indicated otherwise, prior to each test, one $\mathrm{SiC}$ monolithic piece coated with a $300 \mathrm{~nm}$ catalyst film was loaded onto the reactor. Then, the reactor was fed with $200 \mathrm{~mL} \cdot \mathrm{min}^{-1}$ of $1 \% \mathrm{v} / \mathrm{v}$ mixture of $\mathrm{H}_{2}$ in air. The reactor was heated to $420^{\circ} \mathrm{C}$ from the outside using a Hobersal TR0 electric furnace and was kept under this temperature for $30 \mathrm{~min}$. After that, the heating was interrupted and the conversion was measured as a function of the temperature in cooling mode. Temperature was measured by a K-type thermocouple placed at the centre of the packed bed. $\mathrm{The}_{2}$ content in the outlet of the reactor was measured by an HP 5890 chromatograph equipped with a ShinCarbon ${ }^{\circledR}$ packed column and a TCD (thermal conductivity) detector with $\mathrm{N}_{2}$ as the carrier gas.

\section{Results and discussion}




\section{As deposited samples}

The composition control of the as deposited $\mathrm{Pt}-\mathrm{Cu}$ thin films with minimized $\mathrm{Pt}$ consumption was achieved as follows. The planar magnetron cathode operating in unbalanced configuration leads to a sputter-erosion path with the shape of a closed ring on the flat target denoted as the race-track (see Fig. 1b). In a first approximation we can expect to obtain in the deposited film a $\mathrm{Pt} / \mathrm{Cu}$ atomic ratio proportional to the area covered in the race-track by $\mathrm{Pt} v s$. Cu with a correction factor given by the different sputtering yields of both elements under each particular deposition condition. The sputtering yields can be estimated from an on-line tool from the TU Wien ( https://www.iap.tuwien.ac.at/www/surface/sputteryield), showing a smaller sputtering yield for Pt than for $\mathrm{Cu}$ for the case of helium compared to argon. On this basis, two targets of high (more strips) or low (less strips) Pt content were prepared with the $\mathrm{Pt} / \mathrm{Cu}$ area ratios at the race-track summarized in Table 1. The obtained compositions of the Pt$\mathrm{Cu}$ samples determined by ICP-AES reflect the values expected from the considerations above, within the experimental error. This demonstrates that our approach is adequate to obtain films at a desired composition without the use of more expensive pure Pt or Pt-Cu targets. Furthermore, the Pt strips are easier to clean and can be recycled and/or reused after each deposition. Regarding the Ar-sputtered films, the atomic Pt-content is 13 and $41 \%$ for the low and high Pt content samples (named Low Pt-Cu_Ar and High Pt-Cu_Ar, respectively). The thin film prepared using $\mathrm{He}$ also has a low Pt content of 13 at. \% of Pt, and is named Low Pt-Cu_He.

The choice of Ar or He as the process gas influences not only the sputtering yield, and therefore the composition, but also the microstructure of the as-deposited films. Figure 2 compares SEM micrographs of the as-prepared catalysts using Ar and He as sputtering gases. The two catalysts obtained using Ar (high and low Pt content) show a columnar 
structure typical for magnetron-sputtered coatings grown under low adatom mobility conditions where surface shadowing governs the film growth [30]. The cross-section images reveal that these meso-columns are composed by nanocolumns where intra and inter-columnar porosity can be observed. On the other hand, the catalyst prepared using $\mathrm{He}$ as the sputtering gas exhibits a different microstructure. Closed porosity is clearly visible and homogeneously distributed all along the film thickness (Fig. 2 left) as expected from our previous works, where a new bottom-up methodology was described to grow layers with closed pores nanostructure by magnetron sputtering [28, 29, 31]. Similar microstructures (see Fig. S1 in supporting information SI) can be observed for the pure $\mathrm{Cu}$ reference samples fabricated in $\mathrm{He}$ (porous) and $\mathrm{Ar}$ (columnar). EDX measurements, were performed at $20 \mathrm{kV}$ from top-views to estimate the $\mathrm{Pt}$ and $\mathrm{Cu}$ relation in bulk and the results are shown in Table 2. The values were obtained as an average of the composition measured in several representative zones. The bulk composition obtained by SEM/EDX is in agreement with the results obtained by ICP-AES, within the experimental error. Illustrative elemental map images for the Low Pt-Cu_He sample deposited on the $\mathrm{SiC}$ foam are also included in Fig. S2 (supporting information). The homogeneous distribution of $\mathrm{Pt}$ and $\mathrm{Cu}$ indicates the alloy formation, and the quality of the deposition methodology for the fabrication of alloyed catalysts.

XRD measurements were performed and the results are shown in Figure 3. The three Pt$\mathrm{Cu}$ as deposited catalysts show profiles characteristics of the fcc crystal structure as well as the two reference $\mathrm{Cu}$ samples. The $\mathrm{Pt}-\mathrm{Cu}$ (111) reflections are lying between those of pure $\mathrm{Pt}$ (111) and pure $\mathrm{Cu}$ (111). Calculation of the crystallite size using the Scherrer's equation (Table 2) shows that samples deposited using Ar as the sputtering gas (Low Pt$\mathrm{Cu} \_\mathrm{Ar}$ and High Pt-Cu_Ar) have a similar crystallite size (approximately 20-21 nm). On 
the other hand, the sample deposited using $\mathrm{He}$ (Low Pt-Cu_He) has a smaller crystallite size $(7 \mathrm{~nm})$ associated with its closed nanoporous structure.

XPS measurements were performed and the normalized spectra are shown in Figure 4. The study of Pt $4 \mathrm{f}$ level, in particular $4 \mathrm{f}_{7 / 2}$, shows that the platinum in the as deposited samples is essentially metallic $\mathrm{Pt}^{0}(70-71 \mathrm{eV})$ with variable contributions of $\mathrm{Pt}^{\mathrm{II}}(72 \mathrm{eV})$ and $\mathrm{Pt}^{\mathrm{IV}}(74 \mathrm{eV})$ states [32]. The position of $\mathrm{Pt}^{0}$ for the Low Pt-Cu_He/Ar samples is approximately $70.9-71 \mathrm{eV}$, while for the High Pt-Cu_Ar sample is $71.4 \mathrm{eV}$. The study of $\mathrm{Cu} 2 \mathrm{p}$ level shows the existence of $\mathrm{Cu}^{0}, \mathrm{Cu}^{\mathrm{I}}$ and $\mathrm{Cu}^{\mathrm{II}}$ in the three samples. According to the literature, the positions of $2 \mathrm{p}_{3 / 2}$ of $\mathrm{Cu}^{0}$ and $\mathrm{Cu}^{\mathrm{I}}$ are in the range of $932.6-932.8 \mathrm{eV}$ for pure $\mathrm{Cu}$ materials [33]. The presence of $\mathrm{Cu}^{\mathrm{II}}\left(2 \mathrm{p}_{3 / 2}, 933.6 \mathrm{eV}\right)$ is well identified by the strong satellite peak at $+9 \mathrm{eV}$ from the $2 \mathrm{p}_{3 / 2}$ signal [33]. However, it is known that the position of the $\mathrm{Cu} 2 \mathrm{p}$ level is modified upon alloying. Many papers have reported the shift of $\mathrm{Cu}^{0}$ and $\mathrm{Cu}^{\mathrm{I}} 2 \mathrm{p}_{3 / 2}$ levels to lower binding energies, ranging from $931 \mathrm{eV}$ for $\mathrm{Ru}-\mathrm{Cu}$ to 931.9 eV for Pt-Cu samples because of the formation of alloys [34-37]. In our samples, the $\mathrm{Cu} 2 \mathrm{p}_{2 / 3}$ position ranges from $931.0 \mathrm{eV}$ for the High $\mathrm{Pt}-\mathrm{Cu} \_$Ar to $931.2 \mathrm{eV}$ for the Low Pt-Cu_He/Ar samples. This shift to lower binding energies is in accordance with the electron transfer from $\mathrm{Pt}$ to $\mathrm{Cu}$ upon alloying and is also reflected in the shift to higher binding energies of the $\mathrm{Pt}^{4} \mathrm{f}_{7 / 2}$ positions. A similar effect was also reported for Pt alloys with $\mathrm{Ni}$ or Fe [38-39].

Quantification of the XPS spectra allowed for the evaluation of the surface composition (Table 2). All coatings exhibit high amounts of surface oxygen, in the 50-60\% range for the low Pt content samples (Low Pt-Cu_He/Ar) and 35\% for the High Pt-Cu_Ar material. This can be correlated to the amount of $\mathrm{Pt}$ in the samples. Calculation of the $\mathrm{Pt}-\mathrm{Cu}$ atomic ratio in the three samples was performed and the results are also summarized in Table 2. From the comparison of the surface Pt-Cu composition with the bulk composition (EDX 
and ICP), it is possible to conclude that there is a Pt surface segregation effect in the three samples. The Low Pt-Cu_He sample shows the strongest Pt-segregation, followed by the Low Pt-Cu_Ar sample. The degree of Pt segregation in the High Pt-Cu_Ar film is the lowest of the three. This effect can also be interpreted as a result of the lower detectability of the non-noble metal $(\mathrm{Cu})$ at the surface due to its preferential bonding to oxygen.

\section{Dealloyed samples}

Dealloyed samples (d-samples) were obtained by treating the films under concentrated nitric acid for $5 \mathrm{~min}$ as described in the experimental part. Longer dealloying times were tested but they did not produce further compositional changes. After dealloying, the samples were washed thoroughly with deionized water. A comparative SEM characterization before and after dealloying is shown in Fig. 5 for the films deposited on the SiC foam or PTFE membranes. In these porous substrates, the location of a border in the film allowed to visualize the cross section of the catalyst coatings. The microstructure of the dealloyed samples is similar to that of the as-prepared ones. Closed porous and columnar microstructures are to some extent still visible after the dealloying treatment (see the high magnification images at the bottom of Fig. 5). This is consistent with the dealloying process progressing with a diffusive mechanism, thus avoiding the falling apart of the catalytic coating. Indeed, three-dimensional nanoporous bulk or film materials are well reported today [14, 40-41]. The formation of a high amount of cracks and voids on the d-Low Pt-Cu_Ar sample is indicative of the high efficiency of the dealloying process along the film.

The bulk composition of the dealloyed samples was measured by SEM/EDX and ICPAES, and the results are shown in Table 2. Both methods are in accordance within the experimental error. As expected, the overall dealloying process was more efficient for the 
Cu-rich samples (Low Pt-Cu_He and Low Pt-Cu_Ar) compared to High Pt-Cu_Ar. This can be attributed to the easier dissolution of the alloy with a higher content of the less noble metal [21]. The highest degree of the overall Pt-enrichment was observed for the d-Low Pt-Cu_Ar sample in accordance to the SEM images. Dealloyed samples were studied by XRD and the results are shown in Figure 3. The broad diffraction peaks are symmetric, indicating that the obtained structure is uniform. The $\mathrm{Pt}-\mathrm{Cu}(111)$ reflections shift to the Pt (111) position, in accordance with the Pt-enrichment. Diffraction peaks after dealloying broaden with respect to their as-prepared counterparts, indicating a decrease in the size of the crystalline domains. The crystallite size was calculated using the Scherrer's equation and the results are shown in Table 2. The d-High Pt-Cu_Ar sample has the largest crystallite size $(21 \mathrm{~nm})$, while for the d-Low Pt-Cu_He/Ar samples, the size is much smaller (3-4 nm). This correlates well with the efficiency of the dealloying process for the different samples. The amorphous character of the d-Low Pt-Cu_Ar/He samples (especially the former, which has a single broad diffraction peak) does not permit accurate simulations in order to compare the bulk lattice strain before and after dealloying.

The microstructure of the d-Low Pt-Cu_He/Ar samples on SiC (mortar grinded) was also studied by TEM/HRTEM and the representative micrographs are shown in Figure 6. This sample preparation method is destructive, and only permits to study some features such as crystalline domains and grains resulting from the grinding process. At high magnification, both dealloyed samples exhibit characteristic nanoporous microstructures with nanocrystalline domains (clearly visible in the insets of Fig. 6) [16]. The d-Low PtCu_He coating shows 1-4 nm size spherical grains, that are interconnected, mirroring the original closed-porous structure. The d-Low Pt-Cu_Ar sample also shows grains connected to each other with a similar size range (1-4nm), although in this case they are 
not strictly spherical but slightly elongated. The open porous-like structure of this sample is clearly appreciated in the images. HRTEM confirms the results obtained by XRD. The study of several representative images has shown that for both samples the crystal size is approximately 1-4 $\mathrm{nm}$ in accordance to Scherrer's calculations (only the biggest particles in the 1-4 $\mathrm{nm}$ interval contribute to the broad peaks appreciated in the diffractogram). These studies indicate that both d-Low Pt-Cu_He/Ar samples have similar grain and crystal size, and the only structural difference is attributed to the type of porosity (more closed $v s$. more open-like).

XPS surface analysis of d-catalysts was carried out in comparison to the as-prepared ones and the results are shown in Figure 4. The study of the Pt $4 \mathrm{f}$ level shows that after dealloying, the positions of the peaks shift to higher binding energies, according to the oxidation to $\mathrm{Pt}^{\mathrm{II}}$ under the action of concentrated nitric acid. The shift is higher for the samples with lower crystallite size (d-Low Pt-Cu_He/Ar). The Cu 2p level of the d-Low $\mathrm{Pt}-\mathrm{Cu} \_\mathrm{He} / \mathrm{Ar}$ samples is noisy and with low intensity, indicating an efficient depletion of surface $\mathrm{Cu}$ and thus the formation of a Pt-enriched surface. The extent of oxidation of Pt is higher for the samples with initial lower amount of the more noble component (Low $\mathrm{Pt}-\mathrm{Cu} \_\mathrm{He} / \mathrm{Ar}$ ), where dealloying is progressing more efficiently. These samples show negligible amounts of $\mathrm{Pt}^{0}$ and a mixture of $\mathrm{Pt}^{\mathrm{II}}$ and $\mathrm{Pt}^{\mathrm{IV}}$ oxidation states, also in accordance to the crystallite size. The d-High Pt-Cu_Ar sample is still essentially metallic, showing a small decrease in the amount of $\mathrm{Pt}^{0}$ with a concomitant small increase in the amount of $\mathrm{Pt}^{\mathrm{II}}$ and $\mathrm{Pt}^{\mathrm{IV}}$ oxidation states with respect to the as-prepared sample. The position of the $\mathrm{Cu} 2 \mathrm{p}$ level remains almost unchanged upon dealloying. Calculation of the surface composition by XPS (Table 2) shows that after dealloying, the three samples have an almost pure Pt-surface (94-98\% $\mathrm{Pt}_{\text {surface }}$ ). However, compared to their corresponding bulk composition (EDX and ICP), it is clear that for the d-High Pt-Cu_Ar sample, the 
dealloying process was limited to the first surface layers. In contrast, for the d-Low Pt-

$\mathrm{Cu} \_\mathrm{He} / \mathrm{Ar}$ samples, the process occurred also at the bulk, with selective $\mathrm{Cu}$ dissolution observed also in the interior region and not only in the near surface. The Low Pt-Cu_Ar sample shows a uniform composition after dealloying (98\% $\mathrm{Pt}_{\text {surface }} \mathrm{vs}$ 95-92\% $\mathrm{Pt}_{\text {bulk }}$ ), while the dealloyed Low Pt-Cu_He sample exhibits a Pt surface enrichment compared to the bulk (96\% $\mathrm{Pt}_{\text {surface }} \mathrm{vs} 72 \% \mathrm{Pt}_{\text {bulk }}$ ), indicating a higher efficiency of the process on the surface layers than in the interior region. This inhomogeneous vertical thin film composition leads to a compressively strained Pt surface, with increased activity with respect to those more relaxed, homogeneous thin film compositions [22-23.a]. The d-Low $\mathrm{Pt}-\mathrm{Cu} \_\mathrm{He}$ sample is also demonstrated to be stable against aqua regia at $80^{\circ} \mathrm{C}$, while the corresponding dealloyed Ar sputtered samples dissolve within a few minutes at RT. All of these results point to the idea that for the low Pt content samples the closed-porous structure presents a higher kinetic barrier to the dealloying process than the columnar one (open porous-like structure).

\section{Catalytic activity}

\section{As-prepared samples}

Figure 7 shows the conversion vs. temperature curves for the as-prepared samples in comparison to a pure $\mathrm{Cu}$ catalyst (prepared using $\mathrm{He}$ as the sputtering gas) and the reactor itself loaded with bare $\mathrm{SiC}$. As expected, the activity of the Pt-Cu thin films is higher than that of the pure $\mathrm{Cu}$ catalyst, but the three samples only show significant activity above $100^{\circ} \mathrm{C}$. The activity in $\mathrm{L}_{\mathrm{H} 2} \cdot \mathrm{min}^{-1} \cdot \mathrm{g}_{\mathrm{Pt}}^{-1}$ was calculated from the curves at $70^{\circ} \mathrm{C}$ and the results (Table 3) indicate that Low $\mathrm{Pt}-\mathrm{Cu}_{-} \mathrm{He}$ is the most active of the three $\left(2.0 \mathrm{~L}_{\mathrm{H} 2} \cdot \mathrm{min}\right.$ $\left.{ }^{1} \cdot \mathrm{gPt}^{-1}\right)$, which correlates inversely with crystal size (Table 2 ). The activity of both Ar sputtered samples is negligible at that temperature, but a comparison at $50^{\circ} \mathrm{C}$ shows that 
Low Pt-Cu_Ar is more active $\left(1.95 \mathrm{LH}_{2} \cdot \mathrm{min}^{-1} \cdot \mathrm{g}_{\mathrm{Pt}}{ }^{-1}\right)$ than High $\mathrm{Pt}-\mathrm{Cu} \_\mathrm{Ar}$ (negligible activity). For both samples with similar crystal size, the trend can be ascribed to the -0.5 eV shift in the Pt $4 \mathrm{f}$ level of the Low Pt-Cu_Ar sample with respect to High Pt-Cu_Ar, according to our previous studies [7].

\section{Dealloyed samples}

Figure 7 shows also the conversion vs. temperature curves for the as-prepared samples in comparison to the dealloyed ones. The activity of the dealloyed samples shifts to lower temperatures, achieving near room temperature conversion in all cases. The increase in the activity for all of the dealloyed samples with respect to their as-prepared counterparts can be ascribed to the obtention of Pt-enriched, more amorphous and disperse samples. The relative increase in the activity with respect to the as-prepared samples (measured as a decrease in the $\mathrm{T}_{50}$, the temperature at which $50 \%$ conversion is achieved) is higher for the dealloyed Low Pt-Cu_Ar sample than for the others, which can be attributed to the higher efficiency in the dealloying process.

For a comparison between dealloyed samples, the activity (in $\mathrm{L}_{\mathrm{H} 2} \cdot \mathrm{min}^{-1} \cdot \mathrm{g}_{\mathrm{Pt}}{ }^{-1}$ ) was calculated from the curves at $70^{\circ} \mathrm{C}$ and the results are shown in Table 3 . The activity trend

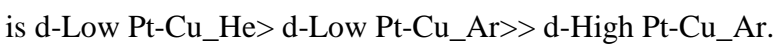

Surface composition does not explain the trend, as the amount of $\mathrm{Pt}_{\text {surface }}$ is similar for the three dealloyed samples (Table 2). The Pt oxidation states do not explain the trend either. Our previous studies on Pt particles over different supports showed that under oxidizing conditions, semi-oxidized Pt-surfaces are more active than the completely oxidized ones [7]. Under this hypothesis, d-High Pt-Cu_Ar should be the most active because of its mostly metallic surface. However, its higher crystallite size might explain its lower activity. The differences in activity between both d-Low Pt-Cu_He/Ar catalysts cannot be explained in terms of crystal size because in both cases the size is similar (3-4nm). The 
open porous structure of d-Low $\mathrm{Pt}-\mathrm{Cu}_{-}$Ar should lead to a higher surface roughening and thus a higher activity, but this does not occur.

Previous studies using synchrotron-based Anomalous X-ray Diffraction (AXRD) and Xray scattering demonstrated that the formation of a Pt-enriched surface and a $\mathrm{Pt}-\mathrm{Cu}$ interior leads to a compressive surface lattice strain, which reduces the Pt-O bond strength, increasing the activity towards the ORR [22-23.a]. The magnitude of the strain is reduced when the thickness of the Pt-enriched surface increases because the structure relaxes more. Based on these works, we explain the higher activity of d-Low Pt-Cu_He ( $\mathrm{Pt}_{\text {surface }} 96 \%, \mathrm{Pt}_{\text {bulk }} 71 \%$ ) with respect to d-Low Pt-Cu_Ar (Ptsurface 98\%, Ptbulk 95\% ). The first sample clearly shows a compositional profile in which the surface is significantly Pt-enriched with respect to the interior, leading to a more strained surface than the latter, which has a more relaxed structure due to its uniform composition [22-23.a]. The correlation between surface lattice strain and activity suggests that for both catalysts under our conditions, breaking the Pt-O bond is the limiting step of the reaction.

The Arrhenius plots were obtained from the linear portion of the conversion-temperature curves and the results are reported in Figure 7. The apparent activation energies (AAEs) were calculated (Table 3). The dealloyed Low Pt-Cu_He sample has the lowest AAE of the three $\left(1 \mathrm{~kJ} . \mathrm{mol}^{-1}\right)$, followed by the d-High Pt-Cu_Ar and d-Low Pt-Cu_Ar samples (21 and $47 \mathrm{kJmol}^{-1}$, respectively). The AAE of the d-Low Pt-Cu_He sample is in the range of the lowest ever reported for this reaction.

It is known that under oxidizing conditions, oxidized surfaces (such as d-Low Pt$\mathrm{Cu} \_\mathrm{He} / \mathrm{Ar}$ ) catalyse the reaction through an Eley-Rideal mechanism, while for semioxidized surfaces (such as d-High Pt-Cu_Ar) the overall mechanism is a mixture of the Eley-Rideal and the Langmuir-Hinselwood pathways [42]. This explains why the comparison of the three AAES is not straightforward, and only the Low Pt-Cu_He/Ar 
samples will be compared. In these samples, weakly adsorbed hydrogen molecules react with chemisorbed oxygen species with no competition for adsorption sites (Eley-Rideal) [42]. The differences in AAEs could be attributed to the distinct lowering of the bonding strength for Pt-O caused by surface strain. Under these conditions, the limiting step must be the desorption of oxygenic species bound to Pt, similar to what occurs in the oxygen reduction reaction (ORR) in fuel cells, and this step is favoured for d-Low Pt-Cu_He [43]. The activity of d-Low Pt-Cu_He $\left(13.15 \mathrm{~L}_{\mathrm{H} 2} \cdot \mathrm{min}^{-1} \cdot \mathrm{g}_{\mathrm{Pt}}{ }^{-1}\right)$ was compared to other catalysts form our previous works and tested under identical conditions. As shown in Table 4, the activity is similar to the one obtained for $(11 \pm 4) \mathrm{nm} \mathrm{Pt}$ nanoparticles $\left(15 \mathrm{LH}_{2} \cdot \mathrm{min}^{-1} \cdot \mathrm{g}_{\mathrm{Pt}}{ }^{-1}\right)$ and lower than that obtained for $(5 \pm 4) \mathrm{nm}$ Pt nanoparticles $\left(32 \mathrm{~L}_{\mathrm{H} 2} \cdot \mathrm{min}^{-1} \cdot \mathrm{g}_{\mathrm{Pt}}{ }^{-1}\right)$ on $\mathrm{SiC}$ supports [7-8]. Compared to other supports, the activity of d-Low Pt-Cu_He is higher than that of $\mathrm{Pt} / \mathrm{Co}_{3} \mathrm{O}_{4}-\mathrm{ZrO}_{2}$ composite $\left(1 \% \mathrm{Pt}\right.$-doped; $\left.3.2 \mathrm{LH} 2 \cdot \mathrm{min}^{-1} \cdot \mathrm{gPt}^{-1}\right)$ but in this case the comparison is not straightforward since the latter catalyst was tested in stoichiometric $\mathrm{H}_{2} / \mathrm{O}_{2}$ ratio, and the reaction rate is intrinsically lower in these conditions [5]. These results show that the activities of the dealloyed supported catalytic coatings are competitive with respect to powdery Pt-impregnated and Pt-doped catalysts reported in the literature.

As stated above, experiments were conducted using a single $\mathrm{SiC}$ monolithic piece coated with $300 \mathrm{~nm}$ thin film catalysts. This film thickness was optimized to obtain a full conversion vs. temperature curve for a proper comparison of the catalysts under nearly isothermal conditions. Under these conditions, the room temperature activity of the dealloyed samples is negligible. To evaluate the RT $\left(23^{\circ} \mathrm{C}\right)$ conversion of the d-Low Pt$\mathrm{Cu} \_\mathrm{He} / \mathrm{Ar}$ catalysts, experiments were conducted by increasing the number of SiCsupported thin-film monolithic catalysts. For both samples, measurable conversion was achieved when loading the reactor with three monolithic catalysts with a consequent 
increase in temperature. The results are shown in Table S.1. (in SI). The highest conversion and increase in temperature $\left(+5^{\circ} \mathrm{C}\right)$ were achieved by the d-Low Pt-Cu_He catalyst $\left(1.85 \mathrm{~L}_{\mathrm{H} 2} \cdot \mathrm{min}^{-1} \cdot \mathrm{gPt}^{-1}\right)$ followed by d-Low Pt-Cu_Ar $\left(0.28 \mathrm{~L}_{\mathrm{H} 2} \cdot \mathrm{min}^{-1} \cdot \mathrm{gPt}^{-1},+0.6^{\circ} \mathrm{C}\right.$ temperature increase), in accordance with the activity trend discussed above.

In terms of a commercial application, durability is very important. For this reason, we tested the durability of the d-Low Pt-Cu_He catalyst in cycles. The results in Figure S.3. (as supporting information) show a certain activation upon cycling, demonstrating that the catalyst is durable, as expected for a Pt catalyst under oxidizing conditions [6-8].

\section{Conclusions}

In this paper, we prepared $\mathrm{Pt}-\mathrm{Cu}$ thin films of controlled microstructure and composition by magnetron sputtering to be used for the first time as catalysts for the combustion of hydrogen under oxidizing conditions. The samples were studied before and after dealloying to obtain more efficient nanoporous Pt-based catalysts. The fabrication of these catalytic films is presented as an alternative to the widely investigated supported nanoparticles. The sputtering deposition of the films was performed using low-cost versatile $\mathrm{Pt}-\mathrm{Cu}$ targets (pure $\mathrm{Cu}$ target with Pt strips), which allowed the selection of the catalyst composition by varying the number of Pt strips and the process gas.

The use of Ar or He as the deposition gases allowed the microstructure of the films to be changed significantly at a constant Pt-composition. Thanks to this, it was possible to evaluate the effect of the microstructure on the activity before and after the dealloying process.

Dealloying permitted us to increase the activity of the samples to reach near roomtemperature conversion. The fabrication of closed-porous $\mathrm{Pt}-\mathrm{Cu}$ samples using $\mathrm{He}$ as the sputtering gas permitted to obtain the highest activity upon dealloying. The closed-porous 
structure is a kinetic barrier for complete $\mathrm{Cu}$ dissolution, yielding a compositional profile in which the surface is significantly Pt-enriched with respect to the interior. This vertical inhomogeneity leads to a more strained surface than that of the Ar-deposited, open porous sample, which has a more relaxed structure due to its uniform composition after dealloying. The catalytic activity of these two samples was interpreted in terms of the Eley-Rideal mechanism, in which desorption of oxygenic species bound to $\mathrm{Pt}$ is the limiting step.

The use of magnetron-sputtered $\mathrm{Pt}-\mathrm{Cu}$ precursors with low Pt content is thus proposed as a strategy to generate nanoporous Pt-based catalysts upon dealloying with high conversion and durability at nearly RT conditions to eliminate the undesired $\mathrm{H}_{2}$ in the exhaust gas of a fuel cell.

\section{Acknowledgments}

Financial support is acknowledged from the Spanish MINECO (grants CTQ201565918-R and MAT2015-69035-REDC, EU co-financed by FEDER), the Junta de Andalucia (grant PE2012-TEP862, EU co-financed by FEDER) and the CSIC (PIE201760E002). TEM measurements were performed at the Laboratory of Nanoscopies and Spectroscopies LANE at the ICMS. The authors thank I. Rosa, J.M. Martinez Blanes, and M.R. Garcia for their very valuable technical support. 


\section{References}

[1] M. Haruta and H. Sano, Int. J. Hydrogen Energy, 6 (1981) 601-608.

[2] I. Wierzba and A. Depiak, Int. J. Hydrogen Energy, 29 (2004) 1303-1307.

[3] K. Ledjeff, Int. J. Hydrogen Energy, 12 (1987) 361-367.

[4] P. A. Deshpande and G. Madras, Phys. Chem. Chem. Phys., 13 (2011) 708-718.

[5] S. A. Singh, K. Vishwanath and G. Madras, ACS Appl. Mater. Interfaces, 9 (2017) 19380-19388.

[6] G. M. Arzac, J. Ramírez-Rico, A. Gutiérrez-Pardo, M. C. Jiménez de Haro, D. Hufschmidt, J. Martínez-Fernández and A. Fernández, RSC Adv., 6 (2016) $66373-66384$.

[7] G. M. Arzac, O. Montes and A. Fernández, Applied Catalysis B: Environmental., 201 (2017) 391-399.

[8] A. Fernández, G. M. Arzac, U. F. Vogt, F. Hosoglu, A. Borgschulte, M. C. Jimenez de Haro, O. Montes and A. Zuttel, Applied Catalysis B: Environmental 180 (2016) 336-343.

[9] V. M. Shinde, G. Madras, Applied Catalysis B: Environmental 132- 133 (2013) $28-38$

[10] C. Zhang, J. Zhang, J. Ma, Int. J. Hydrogen Energy 37 (2012) 12941- 12946.

[11] P.A. Deshpande, G. Madras, Applied Catalysis B: Environmental 100 (2010) 481490. 
[12] H. J. Qiu, L. Peng, X. Li, H. T. Xu and Y. Wang, Corros. Sci., 92 (2015) 16-31.

[13] J. Erlebacher, M. J. Aziz, A. Karma, N. Dimitrov and K. Sieradzki, Nature, 410 (2001) 450-453.

[14] J. Biener, M. M. Biener, R. J. Madix and C. M. Friend, ACS Catal., 5 (2015) $6263-6270$.

[15] H. A. Gasteiger, S. S. Kocha, B. Sompalli and F. T. Wagner, Applied Catalysis B: Environmental, 56 (2005) 9-35.

[16] S. Koh and P. Strasser, J. Am. Chem. Soc., 129 (2007) 12624-12625.

[17] P. Mani, R. Srivastava and P. Strasser, J. Phys. Chem. C, 112 (2008) 2770-2778.

[18] K. C. Neyerlin, R. Srivastava, C. Yu and P. Strasser, J. Power Sources, 186 (2009) 261-267.

[19] P. Strasser, S. Koh, T. Anniyev, J. Greeley, K. More, C. Yu, Z. Liu, S. Kaya, D. Nordlund, H. Ogasawara, M. F. Toney and A. Nilsson, Nature Chemistry., 2 (2010) 454-460.

[20] L. Gan, M. Heggen, R. O’Malley, B. Theobald and P. Strasser, Nano Letters, 13 (2013) 1131-1138

[21] P. Mani, R. Srivastava and P. Strasser, J. Power Sources, 196 (2011) 666-673.

[22] R. Yang, J. Leisch, P. Strasser and M. F. Toney, Chem. Mater., 22 (2010) 47124720.

[23] a.R. Yang, P. Strasser and M. F. Toney, J. Phys. Chem. C, 115 (2011) 90749080. 
b. R.Yang, W. Bian, P.Strasser, M.F. Toney, J. Power Sources, 222 (2013) 169176.

[24] A.Abburi, N. Abrams, W. J. Yeh, J Porous Mater, 19 (2012) 543-549.

[25] V. Godinho, C. Lopez-Santos, T. C. Rojas, D. Philippon, M. C. Jiménez de Haro, S. Lucas and A. Fernández, J. Alloys Compd., 536 (2012) S398-S406.

[26] M. Paladini, G.M. Arzac, V. Godinho, M.C. Jiménez De Haro, A. Fernández. Appl. Catal. B: Environmental, 158-159 (2014) 400-409.

[27] M. Paladini, V. Godinho, G. M. Arzac, M. C. Jiménez de Haro, A. M. Beltrán, A. Con formato: Español (España) Fernández. RSC Adv., 6 (2016) 108611-108620.

[28] V. Godinho, J. Caballero-Hernández, D. Jamon, T. C. Rojas, R. Schierholz, J. García-López, F. J. Ferrer and A. Fernández, Nanotechnology, 24 (2013) 275604 (10pp).

[29] V. Godinho, P. Moskovkin, R. Alvarez, J. Caballero-Hernández, R. Schierholz, B. Bera, J. Demarche, A. Palmero, A. Fernández, S. Lucas, Nanotechnology, 25 (2014) 355705 (11pp).

[30] J. A. Thornton, Ann Rev Mat Sci, 7 (1977) 239-260.

[31] R. Schierholz, B. Lacroix, V. Godinho, J. Caballero-Hernández, M. Duchamp and A. Fernández, Nanotechnology, 26 (2015) 075703 (10pp).

[32] L. K. Ono, J. R. Croy, H. Heinrich and B. Roldan Cuenya, J. Phys. Chem. C, 115 (2011) 16856-16866.

[33] S. Poulston, P. M. Parlett, P. Stone, M. Bowker, Surf. Interface Anal., 24 (1996) 
$811-820$

[34] K. Zhang, Q. Yue, G. Chen, Y. Zhai, L. Wang, H. Wang, J. Zhao, J. Liu, J. Jia and H. Li, J. Phys. Chem. C, 115 (2011) 379-389.

[35] Y. Liao, G. Yu, Y. Zhang, T. Guo, F. Chang and C. J. Zhong, J. Phys. Chem. C, 120 (2016) 10476-10484.

[36] L. Bai, Dalt. Trans., 45 (2016) 4712-4715.

[37] T. Liu, K. Wang, Q. Yuan, Z. Shen, Y. Wang, Q. Zhang, X. Wang, Nanoscale, 9 (2017) 2963-2968.

[38] L. Cao, G. Zhang, W. Lu, X. Qin, Z. Shao, B. Yi, RSC Adv.,6 (2016) 3999340001.

[39] J. Yang, W. Zhou, C. H. Cheng, J. Y. Lee and Z. Liu, ACS Appl. Mater. Interfaces, 2 (2010) 119-126.

[40] R. Jana, A. Bhim, P. Bothra, S. K. Pati and S. C. Peter, ChemSusChem, 6 (2016) 2922-2927.

[41] T. Fujita, P. Guan, K. McKenna, X. Lang, A. Hirata, L. Zhang, T. Tokunaga, S. Arai, Y. Yamamoto, N. Tanaka, Y. Ishikawa, N. Asao, Y. Yamamoto, J. Erlebacher and M. Chen, Nat. Mater., 11 (2012) 775-780.

[42] J. G. Firth, Trans. Faraday Soc., 67 (1971) 212-215.

[43] M. Oezaslan, F. Hasché and P. Strasser, J. Phys. Chem. Lett., 4 (2013) 32733291. 


\section{Figure captions}

Figure 1. Schemes representing (a) the MS deposition geometry and (b) the Pt strips distribution on the $\mathrm{Cu}$ target (the erosion race-track is indicated by the dotted rings).

Figure 2. SEM images (planar view at top, cross section at bottom) of the as-prepared Pt$\mathrm{Cu}$ thin films on Si substrates.

Figure 3. XRD measurements of the as-prepared and dealloyed $\mathrm{Pt}-\mathrm{Cu}$ thin films on $\mathrm{Si}$ substrates.

Figure 4. XPS measurements (normalized spectra) of the as-prepared and dealloyed Pt$\mathrm{Cu}$ thin films on PTFE membrane substrates. Reference binding energy values for the different $\mathrm{Pt}$ and $\mathrm{Cu}$ oxidation states are indicated.

Figure 5. SEM images of the as-prepared (top row) and dealloyed (rows down) Pt-Cu thin films on $\mathrm{SiC}$ or PTFE membrane as substrates

Figure 6. TEM images of the dealloyed Low Pt-Cu thin films. Insets: zoom of the marked areas.

Figure 7. Conversion vs. temperature curves and Arrhenius plots for the $\mathrm{CHC}$ reaction catalysed by the as-prepared and dealloyed Pt-Cu thin films. 


\section{Table Legends}

Table 1. Deposition conditions and bulk composition of the as-prepared $\mathrm{Cu}$ and $\mathrm{Pt}-\mathrm{Cu}$ thin films.

Table 2. Microstructural and chemical characterization of the as-prepared and dealloyed Pt-Cu thin films

Table 3. Kinetic parameters obtained for the $\mathrm{CHC}$ reaction catalysed by the as-prepared and dealloyed Pt-Cu thin films. Comparative data with catalysts in the literature are included. 